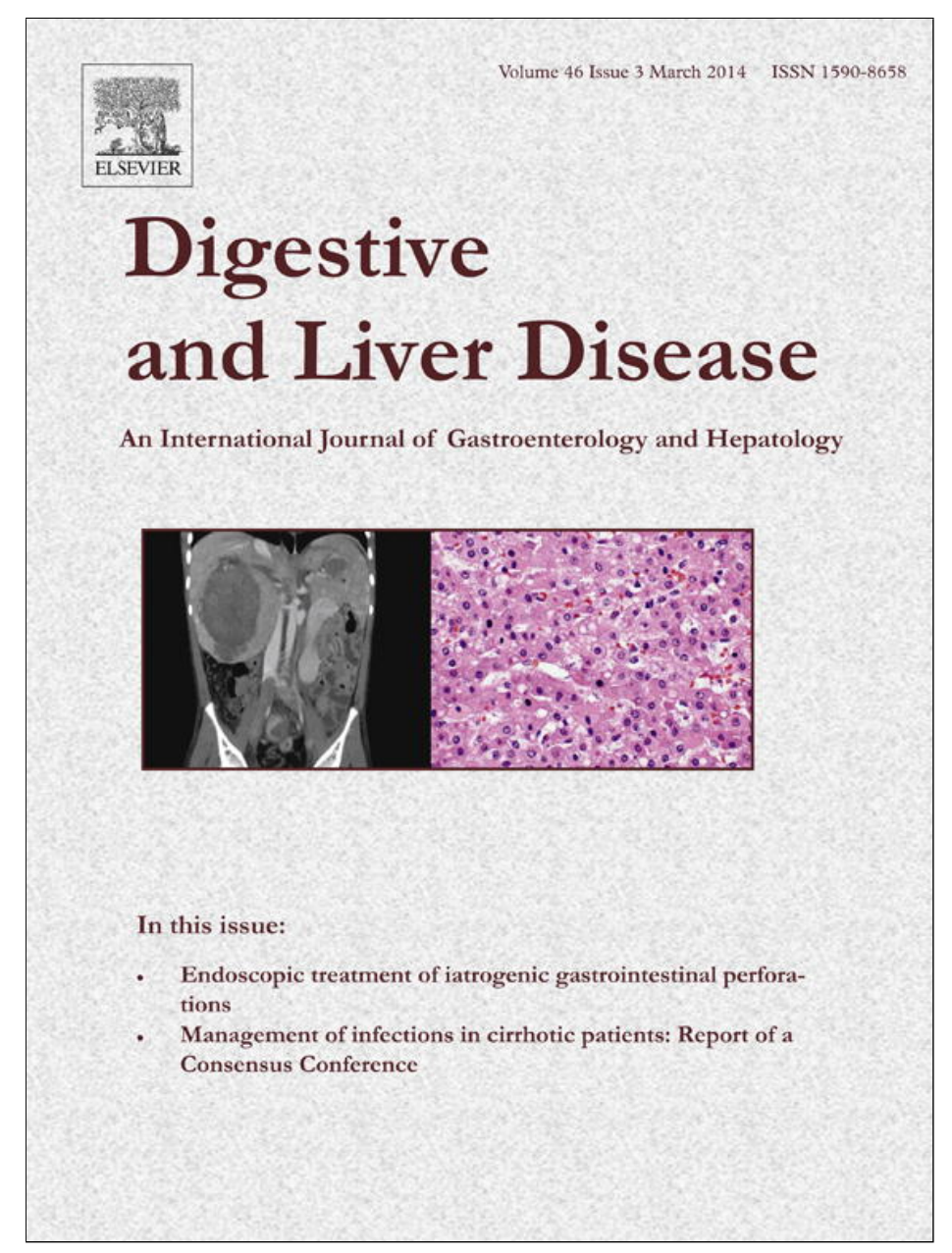

This article appeared in a journal published by Elsevier. The attached copy is furnished to the author for internal non-commercial research and education use, including for instruction at the authors institution and sharing with colleagues.

Other uses, including reproduction and distribution, or selling or licensing copies, or posting to personal, institutional or third party websites are prohibited.

In most cases authors are permitted to post their version of the article (e.g. in Word or Tex form) to their personal website or institutional repository. Authors requiring further information regarding Elsevier's archiving and manuscript policies are encouraged to visit:

http://www.elsevier.com/authorsrights 
Alimentary Tract

\title{
Low incidence but poor prognosis of complicated coeliac disease: A retrospective multicentre study
}

\author{
Federico Biagi ${ }^{\mathrm{a}, *}$, Paolo Gobbi ${ }^{\mathrm{a}}$, Alessandra Marchese ${ }^{\mathrm{a}}$, Edoardo Borsotti ${ }^{\mathrm{a}}$, \\ Fabiana Zingone $^{\mathrm{b}}$, Carolina Ciacci ${ }^{\mathrm{b}}$, Umberto Volta ${ }^{\mathrm{c}}$, Giacomo Caio ${ }^{\mathrm{c}}$, \\ Antonio Carroccio ${ }^{\mathrm{d}}$, Giuseppe Ambrosiano ${ }^{\mathrm{e}}$, Pasquale Mansueto ${ }^{\mathrm{e}}$, Gino R. Corazza ${ }^{\mathrm{a}}$ \\ a Coeliac Centre/First Department of Internal Medicine, Fondazione IRCCS Policlinico San Matteo, University of Pavia, Italy \\ ${ }^{\mathrm{b}}$ Department of Medicine and Surgery, Gastrointestinal Immune Diseases Centre, University of Salerno, Italy \\ ' Coeliac Centre/Department of Clinical Medicine, St. Orsola-Malpighi University Hospital, Bologna, Italy \\ ' UO di Medicina, Ospedali Civili Riuniti di Sciacca, University of Palermo, Italy \\ e Internal Medicine, University of Palermo, Italy
}

\section{A R T I C L E I N F O}

\section{Article history:}

Received 21 May 2013

Accepted 15 October 2013

Available online 20 November 2013

\section{Keywords:}

Celiac disease/epidemiology

Gluten

Incidence

Prognosis

Risk assessment

\begin{abstract}
A B S T R A C T
Background: Coeliac disease is a chronic enteropathy characterized by an increased mortality caused by its complications, mainly refractory coeliac disease, small bowel carcinoma and abdominal lymphoma. Aim of the study was to study the epidemiology of complications in patients with coeliac disease. Methods: Retrospective multicenter case-control study based on collection of clinical and laboratory data. The incidence of complicated coeliac disease was studied among coeliac patients directly diagnosed in four Italian centres. Patients referred to these centres after a diagnosis of coeliac disease and/or complicated coeliac disease in other hospitals were therefore excluded.

Results: Between 1/1999 and 10/2011, 1840 adult coeliac patients were followed up for 7364.3 personyears. Fourteen developed complications. Since five patients died, at the end of the observation period (10/2011), the prevalence of complicated coeliac disease was $9 / 1835$ (1/204, $0.49 \%, 95 \% \mathrm{CI} 0.2-0.9 \%)$. The annual incidence of complicated coeliac disease in the study period was $14 / 7364(0.2 \%, 95 \% \mathrm{Cl} 0.1-0.31 \%)$. Although complications tend to occur soon after the diagnosis of coeliac disease, Kaplan-Meier curve analysis showed that they can actually occur at any time after the diagnosis of coeliac disease.

Conclusions: Complications of coeliac disease in our cohort were quite rare, though characterised by a very high mortality.
\end{abstract}

(c) 2013 Editrice Gastroenterologica Italiana S.r.l. Published by Elsevier Ltd. All rights reserved.

\section{Introduction}

Coeliac disease (CD), a chronic enteropathy due, in genetically predisposed individuals, to the intake of gluten, is well known as being characterized by both a high prevalence and an increased mortality $[1,2]$. Although in the great majority of patients the prognosis of this disease is excellent, and most coeliac patients die for causes unrelated to $\mathrm{CD}$, some of these patients may develop a series of serious complications, such as refractory CD type 1 and type 2 (RCD1 and RCD2), ulcerative jejunoileitis (UJI), enteropathyassociated T-cell lymphoma (EATL), abdominal B cell lymphoma $(\mathrm{ABL})$, and small bowel carcinoma (SBC), which dramatically reduce

\footnotetext{
This project was supported by a grant from the Fondazione Celiachia "Studio di possibili fattori ambientali e sviluppo di nuove strategie terapeutiche nelle complicanze della malattia celiaca". The funding source had no role.

* Corresponding author at: Coeliac Centre/1st Department of Internal Medicine, Fondazione IRCCS Policlinico San Matteo, P.le Golgi, 19, I-27100 Pavia, Italy.

Tel.: +390382 502973; fax: +390382502618.

E-mail address: f.biagi@smatteo.pv.it (F. Biagi).
}

the prognosis [3-7]. In particular, the five-year survival rate is between $80 \%$ and $96 \%$ in patients with RCD1, between $40 \%$ and $58 \%$ in patients with RCD2 and drops to less than $20 \%$ in patients with CD complicated by EATL [8-13].

The first papers on the molecular diagnosis of complicated CD (CCD) were published more than 10 years ago [14], and since then several papers were published on this subject [4-19]. Despite these achievements, the literature still provides only minor and insufficient indications on the incidence of these conditions in patients with CD [8,15-19]. The reason for this lack of data can probably be attributed to the fact that most patients with CCD are sent to large referral centres. Similarly, a considerable number of patients with non-complicated $C D$ are also referred to these centres. While sending all these patients to such referral centres certainly makes it easier to study the disease, it also introduces an inevitable selection bias and thus makes an epidemiological study of CCD extremely difficult.

Our aim was to resolve this bias by studying how many patients with $\mathrm{CD}$ diagnosed directly in a single centre subsequently develop a complicated form of $\mathrm{CD}$. 


\section{Patients and methods}

A retrospective multicenter case-control study based on collection of clinical and laboratory data was carried out in four Italian referral centres for the study of $C D$ and its complications. In each of these centres it was calculated how many patients with $C D$ were diagnosed directly in the centre between January 1999 and October 2011. The patients were diagnosed on the basis of a duodenal biopsy showing a certain degree of villous atrophy and of positive antitransglutaminase/antiendomysial antibodies. This means that all patients with $C D$ that were seen at the centre to obtain a certificate entitling them to gluten-free products through the Italian National Health Service, for confirmation of a diagnosis made elsewhere or for suspected CCD, were excluded. Among all the remaining patients, those whose malabsorption symptoms persisted despite at least 12 months of a gluten-free diet and in whom a diagnosis of complicated CD was made were selected. More specifically, the diagnosis of RCD2 was based on a flat duodenal mucosa not responding to 12 months on a gluten-free diet and evidence of an aberrant intraepithelial lymphocyte population and/or gamma chain $\mathrm{T}$ cell monoclonal rearrangement; diagnosis of RCD1 was based on a flat duodenal mucosa not responding to 12 months on a gluten-free diet but without the diagnostic criteria for RCD2; finally, the diagnoses of EATL, ABL, UJI, and SBC were based on morphological criteria [9-12]. For all these patients, the following information was collected: sex, date of birth, date of diagnosis of $C D$, date of the last examination at the centre, date of diagnosis of complications of $\mathrm{CD}$, if applicable, and date of death, if applicable. In this article, the term "cases" indicates patients with CD who subsequent developed a complication while the term "controls" indicates patients with $\mathrm{CD}$ who did not subsequently develop a complication.

The study was approved by the ethics committee of the Fondazione IRCCS Policlinico San Matteo.

\section{Statistics}

The incidence of complication was evaluated both on the whole patient population and on the subsets from each of the four referral Centres. Differences of incidence were analysed with $2 \times K$ contingency tables, applying Fisher's exact test in cases of too small numbers [19]. The 95\% confidence intervals were calculated according to Poisson's exact test.

Curves of duration of follow-up and complication-free survival were calculated according to the Kaplan-Meier technique and, when applicable, differences were analysed with the log-rank test $[20,21]$.

The complication-free survival was further analysed through univariate and bivariate regressions applied to the proportional hazards model [22], with sex and age at diagnosis of CD as covariates. The relative risk, related to the adequacy of the model and calculated per single measurement unit of the covariate, was derived from the natural exponential of the partial regression coefficient.

The analyses were performed using the Stat View 5.0 software package (Abacus Concepts, Berkeley, California, 1995) for Macintosh.

\section{Results}

Between January 1999 and October 2011, a total of 2071 adult patients with $C D$ were diagnosed in the four centres participating in the study. Two-hundred and thirty-one of them were not seen after the initial diagnosis of $\mathrm{CD}$ and were considered to be lost to followup. The remaining 1840 ( $1390 \mathrm{~F}$, mean age 37.0 years \pm 11.9 ) had a

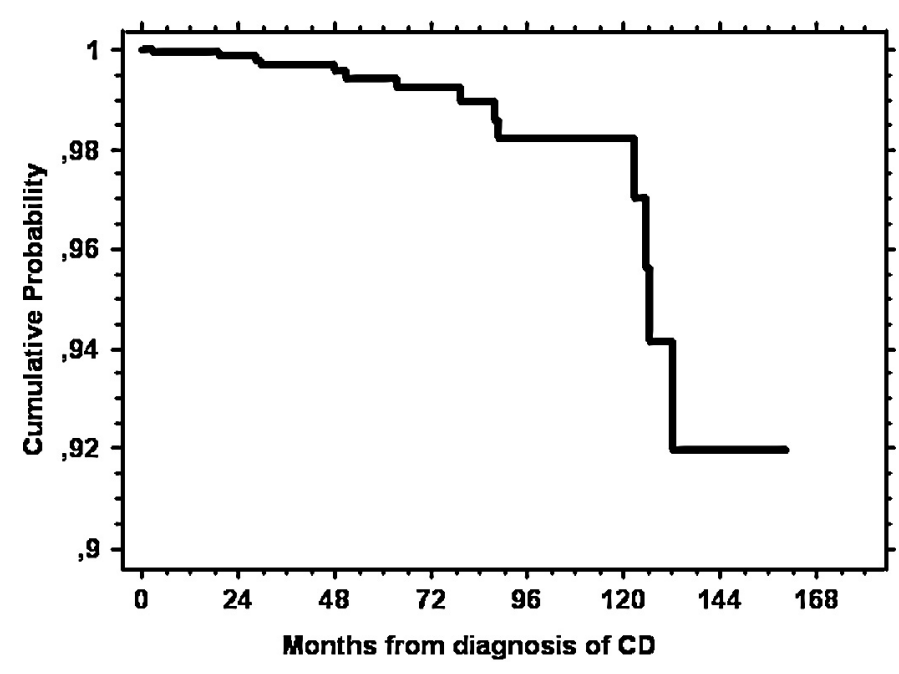

Fig. 1. Kaplan-Meier curve showing the complication-free survival in patients with coeliac disease. The onset of complications is a rare event but can occur even many years after the diagnosis of coeliac disease.

cumulative follow-up of 7364.3 person-years (mean follow-up 48.0 months, 95\% CI 0.03-160.5). During this period, 14 of these 1840 patients developed a CD-related complication $(11 \mathrm{~F}$, mean age at diagnosis of CCD 61.1 years $\pm 12.2 ; 5$ cases of RCD1, 3 SBC, 2 RCD2, 2UJI, 1 EATL, $1 \mathrm{ABL}$ ). All 14 had severe malabsorption symptoms and 5 of them died ( $3 \mathrm{~F}$, mean age at death 69.6 years $\pm 8.2 ; 3$ cases of RCD1, 1 EATL, $1 \mathrm{SBC}$ ). Since none of the 1826 controls (1379 F, mean age at diagnosis of $C D 35.4$ years \pm 11.4 ) died, at the end of the observation period (October 2011), the prevalence of CCD in our population of patients with CD was therefore 9/1835 (1/204, $0.49 \%, 95 \%$ CI $0.2-0.9 \%$ ). The annual incidence of CCD in our study period was $1 / 526.3(0.2 \%, 95 \% \mathrm{CI} 0.1-0.31 \%)$.

Fig. 1 shows the Kaplan-Meier curve for complication-free cumulative survival. This analysis confirms that the onset of complications is fortunately a rare event that can, however, also occur many years after the diagnosis of $\mathrm{CD}$.

Age at diagnosis of $C D$ in the cases was significantly higher compared with age at diagnosis of $\mathrm{CD}$ in the controls $(59.2 \pm 12.2$ years vs. $36.8 \pm 12.4 ; p<0.0001$ ). Fig. 2 shows that a value of age at diagnosis of $C D$ between the two means (48 years) discriminates the complication-free survival very well. The analysis according to the proportional risks model shows that the age at diagnosis

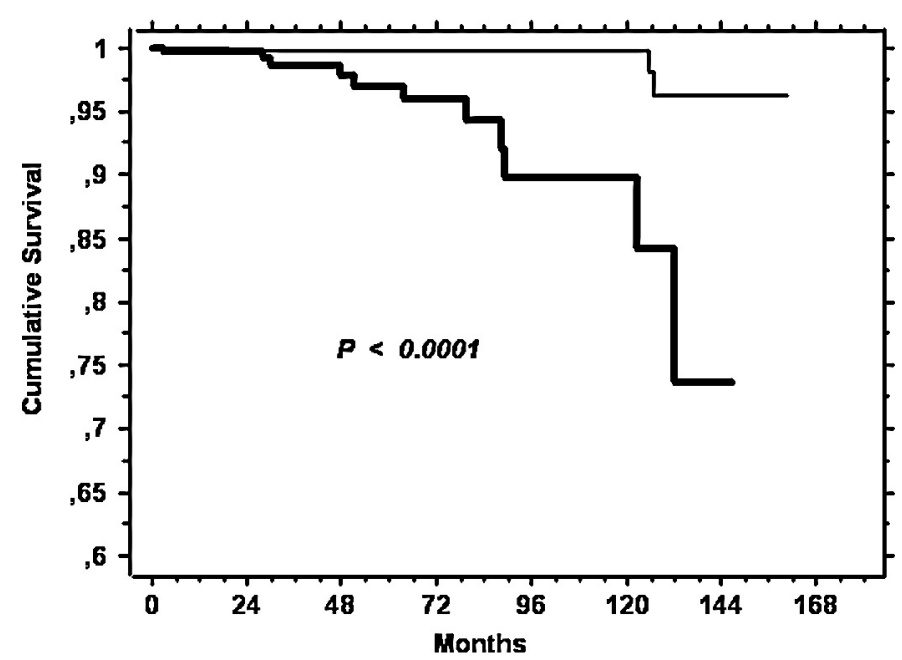

Fig. 2. Complication-free survival according to age at diagnosis of coeliac disease. Thick line $>48$ years; thin line $\leq 48$ years. 
Table 1

Bivariate analysis of the complication-free survival according to the proportional hazards model showing that age at diagnosis of coeliac disease is closely correlated with complication-free survival, whereas sex is not.

\begin{tabular}{lccc}
\hline & Coefficient & Chi-square & $p$ \\
\hline Age & 0.053 & 28.5666 & $<0.0001$ \\
Sex & -0.300 & 0.245 & 0.62 \\
\hline
\end{tabular}

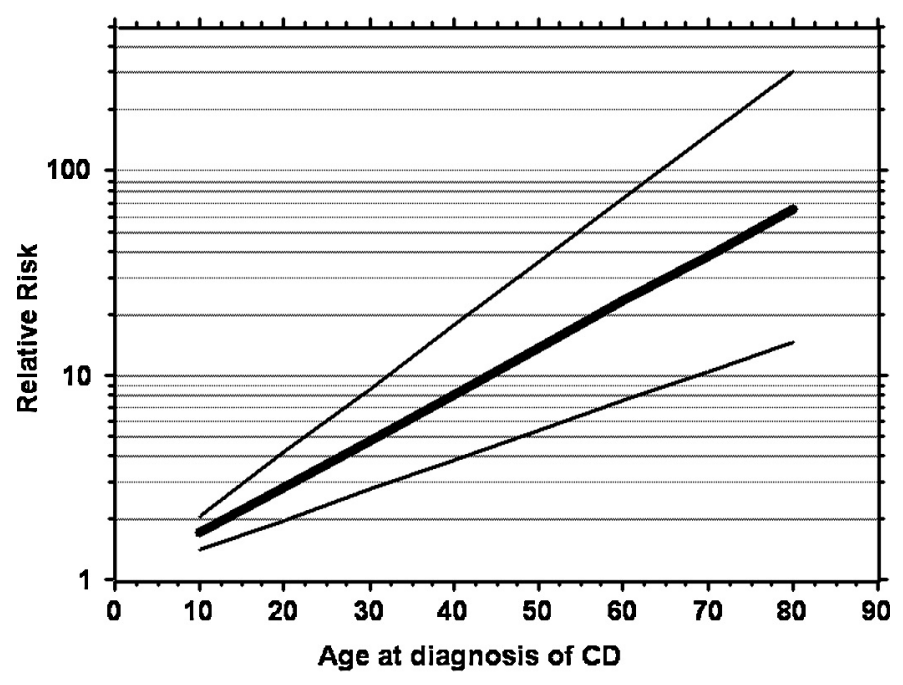

Fig. 3. The thick central line shows the estimated risk of complications on the basis of age at diagnosis of coeliac disease; the thin external lines show the $95 \%$ confidence interval. Age at diagnosis of coeliac disease is linked to an increased risk of complicated coeliac disease, though not patient age.

of $\mathrm{CD}$, unlike sex, is closely related with complication-free survival (Table 1). The close correlation between the age and the complication-free survival made it possible to assess the relative hazard of complication. Fig. 3 shows the estimated complication risk based on age at diagnosis of $\mathrm{CD}$.

\section{Discussion}

Although it has been known for many years that the increased mortality in CD is due to its feared complications [23], the literature reports very few epidemiological data on these complications [8,15-19]. This lack of data can undoubtedly be attributed both to the significant selection biases in these series of patients and to the difficulties caused by the lack of uniform diagnostic criteria for the various forms of CCD $[15,16]$.

Our study is the first to evaluate the incidence of CCD in patients with $C D$. This was a multicentre study involving almost 2000 patients from four CD centres distributed throughout Italy. Although we took into account only coeliac patients directly diagnosed in our centres and excluded those patients diagnosed elsewhere and then referred to us, our results could overestimate the risk of complications. Despite this, our results show that the complications of $\mathrm{CD}$ are rare but that they can occur even many years after the diagnosis of $\mathrm{CD}$ and confirm that these complications have a high mortality rate [2,8-13]. Since we did not record any death from other causes among either cases or controls (this means none of them died from cardiovascular disease, infections, any type of cancer, respiratory disease etc.), our results reflect the specific mortality of coeliac patients due to CCD itself. Finally, we recorded only 14 cases of complications, so it was obviously not possible to study the epidemiology of the various forms of CCD. RCD was the most common form of CCD ( $50 \%$ of the cases).

It has been known for some time that the risk of complications in patients with $\mathrm{CD}$ is linked to a series of factors such as age at diagnosis of $C D$, the diagnostic delay of $C D$, the strictness of the gluten-free diet, the clinical form of $C D$ and the homozygosity for DQ2 [2,18,23-26]. Our results confirmed a strong correlation between age at diagnosis of $\mathrm{CD}$ and the risk of developing a complicated form of CD. Fig. 3 does in fact show that the risk of developing complications increases logarithmically with the increase in age. On the other hand, we could not confirm the recently shown correlation between sex and risk of developing CCD [18]. The retrospective and multicentre nature of this study, carried out over a period of almost 13 years, did not allow us to study a correlation with other parameters such as the strictness of gluten-free diet, the clinical form of $\mathrm{CD}$ and the homozygosity for DQ2.

Due to its retrospective nature, our study was hindered by inevitable difficulties in data collection and thus by the inevitable controls lost to follow-up. Since we cannot exclude the possibility that at least some of these controls were lost to follow-up precisely because they developed a complication, we must consider that our results may underestimate the true situation. On the other hand, we noted that the vast majority of coeliac patients lost to follow-up were all enrolled in one centre where histological recovery of the duodenal mucosa while on a GFD is not routinely checked. We therefore compared the results of this single centre with the results of the other three centres grouped together. No significant difference emerged (data not shown).

All these problems could be resolved by a prospective study. However, our results show that it would be necessary to enrol a very large number of coeliac patients $(>1000)$ who must be carefully followed for at least 10-15 years in order to record the onset of any complications. We therefore believe that organizing such a study would be extremely difficult.

We conclude the complications of $C D$ are very serious conditions that can occur many years after the initial diagnosis of CD. There is a strong correlation between risk of complication and age at diagnosis of $\mathrm{CD}$. Fortunately, these complications are quite rare.

\section{Conflict of interest statement}

All the authors declare that they have no conflicts of interest.

\section{Acknowledgments}

We are grateful to Susan West for reading and correcting the manuscript.

\section{References}

[1] Biagi F, Klersy C, Balduzzi D, et al. Are we not over-estimating the prevalence of coeliac disease in the general population. Annals of Medicine 2010;42:557-61.

[2] Biagi F, Corazza GR. Mortality in celiac disease. Nature Reviews Gastroenterology and Hepatology 2010;15:8-16, 2.

[3] Biagi F, Lorenzini P, Corazza GR. Literature review on the clinical relationship between ulcerative jejunoileitis, coeliac disease, and enteropathy-associated T-cell. Scandinavian Journal of Gastroenterology 2000;35:785-90.

[4] Leslie LA, Lebwohl B, Neugut AI, et al. Incidence of lymphoproliferative disorders in patients with celiac disease. American Journal of Hematology 2012;87:754-9.

[5] Elfström P, Granath F, Ye W, Ludvigsson JF. Low risk of gastrointestinal cancer among patients with celiac disease, inflammation, or latent celiac disease. Clinical Gastroenterology and Hepatology 2012;10:30-6.

[6] Grainge MJ, West J, Card TR, Holmes GK. Causes of death in people with celiac disease spanning the pre- and post-serology era: a population-based cohort study from Derby, UK. American Journal of Gastroenterology 2011 May;106:933-9.

[7] Rampertab SD, Forde KA, Green PH. Small bowel neoplasia in coeliac disease. Gut 2003;52:1211-4.

[8] Roshan B, Leffler DA, Jamma S, et al. The incidence and clinical spectrum of refractory celiac disease in a north American referral center. American Journal of Gastroenterology 2011;106:923-8.

[9] Malamut G, Afchain P, Verkarre V, et al. Presentation and long-term follow-up of refractory celiac disease: comparison of type I with type II. Gastroenterology 2009;136:81-90. 
[10] Al-Toma A, Verbeek WH, Hadithi M, et al. Survival in refractory coeliac disease and enteropathy-associated T-cell lymphoma: retrospective evaluation of single-centre experience. Gut 2007;56:1373-8.

[11] Daum S, Ipczynski R, Schumann M, et al. High rates of complications and substantial mortality in both types of refractory sprue. European Journal of Gastroenterology and Hepatology 2009;21:66-70.

[12] Rubio-Tapia A, Kelly DG, Lahr BD, et al. Clinical staging and survival in refractory celiac disease: a single center experience. Gastroenterology 2009;136:99-107.

[13] Gale J, Simmonds PD, Mead GM, et al. Enteropathy-type intestinal T-cell lymphoma: clinical features and treatment of 31 patients in a single center. Journal of Clinical Oncology 2000;18:795-803.

[14] Cellier C, Delabesse E, Helmer C, et al. Refractory sprue, coeliac disease, and enteropathy-associated T-cell lymphoma. French Coeliac Disease Study Group. Lancet 2000;356:203-8.

[15] Biagi F, Corazza GR. Defining gluten refractory enteropathy. European Journal of Gastroenterology and Hepatology 2001;13:561-5.

[16] Malamut G, Cellier C. Is refractory celiac disease more severe in old Europe American Journal of Gastroenterology 2011;106:929-32.

[17] West J. Celiac disease and its complications: a time traveller's perspective. Gastroenterology 2009;136:32-4.

[18] Leffler DA, Dennis M, Hyett B, et al. Etiologies and predictors of diagnosis in nonresponsive celiac disease. Clinical Gastroenterology and Hepatology 2007; 5:445-50.
[19] Armitage P, Berry G. Statistical methods in medical research. 2nd ed. Oxford (GB): Blackwell Scientific Publication; 1988. p. 205-13.

[20] Kaplan EL, Meier P. Non parametric estimation from incomplete observations Journal of the American Statistical Association 1958;53:457-81.

[21] Peto R, Pike MC, Armitage P, et al. Design and analysis of randomized clinical trials requiring prolonged observation of each patient. II. Analysis and examples. British Journal of Cancer 1977;35:1-39.

[22] Cox DR. Regression models and life tables. Journal of the Royal Statistical Society: Series B 1972;34:187-220.

[23] Corrao G, Corazza GR, Bagnardi V, et al. Mortality in patients with coeliac disease and their relatives: a cohort study. Lancet 2001;358:356-61.

[24] Murray JA, Moore SB, Van Dyke CT, et al. HLA DQ gene dosage and risk and severity of celiac disease. Clinical Gastroenterology and Hepatology 2007;5:1406-12.

[25] Al-Toma A, Goerres MS, Meijer JW, et al. Human leukocyte antigen-DQ2 homozygosity and the development of refractory celiac disease and enteropathy associated T-cell lymphoma. Clinical Gastroenterology and Hepatology 2006;4:315-9.

[26] Biagi F, Bianchi PI, Vattiato C, et al. The influence of HLA-DQ2 and DQ8 on severity in celiac disease. Journal of Clinical Gastroenterology 2012;46: $46-50$ 